\title{
What constitutes an excellent allied health care professional? A multidisciplinary focus group study
}

\author{
This article was published in the following Dove Press journal: \\ Journal of Multidisciplinary Healthcare \\ 7 September 2013 \\ Number of times this article has been viewed
}

\section{Wolter Paans \\ Inge Wijkamp \\ Egbert Wiltens \\ Marca $\vee$ Wolfensberger}

Research and Innovation Group Talent Development in Higher Education and Society, Hanze University of Applied Sciences, Groningen, The Netherlands.

Correspondence: Wolter Paans Hanze University of Applied Sciences, Eyssoniusplein 18, Groningen, The Netherlands, PO Box 3109 , 970I DC Groningen, The Netherlands $\mathrm{Tel}+3$ I 505953534

Fax +3I 505953600

Email w.paans@pl.hanze.nl
Background: Determining what constitutes an excellent allied health care professional (AHCP) is important, since this is what will guide the development of curricula for training future physical therapists, oral hygienists, speech therapists, diagnostic radiographers, and dietitians. This also determines the quality of care.

Aim: To describe perspectives of AHCPs on which characteristics are commonly associated with an excellent AHCP.

Methods: AHCPs' perspectives were derived from three focus group discussions. Twentyone health care professionals participated. The final analysis of the focus group discussions produced eight domains, in which content validity was obtained through a Delphi panel survey of 27 contributing experts.

Results: According to the survey, a combination of the following characteristics defines an excellent AHCP: (1) cognizance, to obtain and to apply knowledge in a broad multidisciplinary health care field; (2) cooperativity, to effectively work with others in a multidisciplinary context; (3) communicative, to communicate effectively at different levels in complex situations; (4) initiative, to initiate new ideas, to act proactively, and to follow them through; (5) innovative, to devise new ideas and to implement alternatives beyond current practices; (6) introspective, to self-examine and to reflect; (7) broad perspective, to capture the big picture; and (8) evidencedriven, to find and to use scientific evidence to guide one's decisions.

Conclusion: The AHCPs perspectives can be used as a reference for personal improvement for supervisors and professionals in clinical practice and for educational purposes. These perspectives may serve as a guide against which talented students can evaluate themselves.

Keywords: clinical excellence, focus group, health care, honors programs, multidisciplinary care

\section{Introduction}

In the Netherlands, allied health care professionals (AHCPs) attaining bachelor's degrees comprise a wide-ranging group, consisting of dietitians, physiotherapists, exercise therapists, speech and language therapists, radiographers, and oral hygienists. ${ }^{1}$ Although this is a diverse group, all AHCPs face similar societal and professional pressures that drive change in the delivery of health care. Some of the prominent pressures evident now are an aging population; lifestyle changes; and advances in diagnostic, intervention, and care opportunities. ${ }^{2,3}$ Each AHCP has to adjust his perspective on delivering high-quality care if he or she is to stay abreast of these changes. AHCPs can achieve this by learning how to convey high-quality, efficient, effective care in complex health care situations. The interest in producing "excellent allied health care 
professionals" in the clinic and understanding what underpins their success has become an active area of research in universities. This has led to new ideas on how to deliver efficient, effective, high-quality care in clinical practice. The term "excellent professional" has not been explicitly defined in the literature, nor is it clear how the concept has been interpreted in the field of AHCPs.

What are the characteristics of an excellent AHCP? Answering this question is vital now, because guidance is required to shape newly launched honors programs for topnotch students in bachelor education in the Netherlands. An honors program is an extended curriculum provided by universities for motivated and talented students. Such a curriculum usually includes multidisciplinary topics, intensive courses presented by expert lecturers, small group discussions, and liberal choices in study possibilities. By using such education programs for talented students, it may be possible to positively influence the students' growth toward excellence. ${ }^{4}$ However, evidence in the field of health care education supporting this notion is lacking.

\section{Background}

The term "professional excellence" implies specific and, potentially, superior attributes, activities, and status. ${ }^{5}$ There may be cultural and international variance to the understanding of what is an excellent professional. Professional excellence refers to a professional role in a broad sense related to a qualification of a professional in (clinical) practice. The educational preparation of excellent professionals can be seen from the perspective of undergraduate courses, extended curriculum courses, as well as postgraduate courses..$^{2,4,5}$ The excellent professional is a professional with competencies related to higher-order reasoning, personal qualities, skills, values, and beliefs. ${ }^{6}$ According to Mieg, "professionalism refers to engagement for a profession, for instance, by setting or defining professional standards of a field or developing its organizational and educational structures." "7 Professionals are relatively autonomous group members that claim jurisdiction over a certain class of tasks; they tend to organize themselves, and they create scientific and content-related networks. ${ }^{8}$

Ericsson $^{9}$ and Mieg $^{7}$ state that professionalism is defined by "professional engagement" (ie, being dynamic in your field); whereas, excellence is correlated with having competencies at an expert level in several areas. Being an "expert" and having "expertise" can be seen as antecedents to the concepts of professionalism and excellence. .,7,10 $^{5,10}$
An expert level of qualification is required for individuals interested in developing expertise and in demonstrating a superior level of knowledge and competencies. ${ }^{10}$ Sternberg ${ }^{11}$ Dweck, ${ }^{12}$ and Benner ${ }^{10}$ state that metacognitive knowledge, high-quality skills, social recognition, self-esteem, confidence, and flexibility are important domains for developing expertise. They also state that performing at a high level in these domains is critical for becoming an expert. Benner ${ }^{10}$ connects the use of "intuition" and life and work experience to expertise. Additional theoretical issues were discussed by Benner, ${ }^{10}$ such as those relating to communication skills, leadership skills, decision-making skills, teamwork, and situational awareness. Courtney ${ }^{5}$ points out that professionalism is a dimension of the attribution or perceived social recognition of expertise and becoming an expert. According to Lovecky, ${ }^{13}$ the concept of a "gifted adult" may be related to the notion of an excellent professional.

Five traits of gifted adults are mentioned by Lovecky: (1) divergence, having a unique way of looking at problems; (2) excitability, the ability to devote a remarkable amount of energy into new projects; (3) sensitivity, the ability to develop intense passion for issues in which they are interested; (4) perceptivity, the ability to view complex tasks as being easy to accomplish; and (5) entelechy, having a powerful drive to achieve self-actualization. ${ }^{13}$

It is unknown whether the characteristics of gifted adults are, to some extent, related to the characteristics defining the conceptual framework of an excellent professional. To identify and deliver the best quality of care for the patient, frameworks focusing on the structure and content of professional competence are needed. ${ }^{14}$

Clarifying the meaning of "professional excellence" and determining whether excellent and expert professionals differ are increasingly viewed as being important, especially for honors programs, which prepare students to be excellent professionals. ${ }^{15,16}$ To guide students in this direction, these programs need to leverage the students' capacities, teaching them the attitudes, knowledge, and competencies needed to be excellent professionals in their clinical practice. ${ }^{15,16}$ This will enable recent graduates to provide quality care and to maintain its continuity.

How experienced AHCPs perceive the concept of "excellent professional" is unknown. ${ }^{17,18}$ It is also unknown what AHCPs expect from excellent professionals. Explorative research in this area is needed to bridge the gap between the content of honors programs for gifted health care sciences students and the expectations of AHCPs in clinical environments. 


\section{Methods}

\section{Aim}

The aim of the study was to establish what constitutes an excellent AHCP, as determined by the perspectives of practicing AHCPs. The overarching goal was to use characteristics identified by the AHCPs to formulate a conceptual profile. Our hope would be that professionals and supervisors in clinical practice, students enrolled in education or honors programs for gifted students, and teachers, could all use this profile as a reference tool. For professionals and students, the profile could serve as a basis for self-reflection and stimulus for improvement. For teachers, it could be used to guide students' attitudes and to build competencies, stimulating students to become excellent health care professionals.

As this study is part of a larger study toward professional excellence in several other professions, such as nursing, primary education, and social work, we aim to determine possible general and specific characteristics of what can be seen as an excellent professional in the near future.

\section{Focus group design}

A multidisciplinary focus group design was used to explore AHCPs' perspectives as revealed in group discussions. ${ }^{19}$ The clarification of views through group discussions may reveal information that would not have emerged in a survey or in individual in-depth interviews. ${ }^{20}$ The multidisciplinary approach aimed to include a well-balanced variety of AHCPs' health care settings. This group context aimed at making the sessions dynamic to be able to share a diversity of perceptions. A topic guide was constructed and used to facilitate the discussion among the participants and to help them focus on characteristics that define an excellent professional. The framework of the topic guide was based on distinguishing perceptible characteristics (performance, knowledge, attitude, disposition, interference) that identify an excellent professional. Subsequently, these characteristics were grouped according to theoretical topics in the literature: experience; communication; leadership; decision-making; teamwork; and situational awareness..$^{5-7,10}$ The main question posed in the focus groups was: "What do you think is an excellent professional in your health care domain?" Examples of more specific questions were: "in your opinion, what is the difference between an excellent AHCP and an average or mediocre AHCP?" and "in your opinion, what is the difference between an expert AHCP and an excellent AHCP?"

\section{Sampling}

Participants lived in the Netherlands. Selections were made by sending an email to members of the Hanze University allied health care network and by snowball sampling.

Professionals were selected based on the following inclusion criteria: (1) working in clinical practice as a registered AHCP (eg, physical therapist, oral hygienist, speech therapist, diagnostic radiographer, or dietitian); and (2) willing to participate in a multidisciplinary focus group discussion (lasting a maximum of 90 minutes) about personal opinions on professional excellence. Professionals were given information in advance about the nature of the research project as well as the methods used. Contact information for the research team was included in case the participants had questions about the study.

Three focus group discussions were organized between October 2011 and January 2012, with a convenience sample of 21 AHCPs (nine in Group I, five in Group II, and seven in Group III). Of these, there were six physical therapists, two oral hygienists, seven speech therapists, four diagnostic radiographers, and two dietitians. All participants were involved in the care of patients in clinical practice. All participants had at least a bachelor-level of education; 16 participants had more than 10 years of experience in their field. The work experience of five participants was at least 5 years. Of the participants, $76 \%$ (16) were female. The mean (standard deviation) age of the participants was 39 (9) years.

\section{Data collection}

Each of the three focus groups discussed for approximately 90 minutes the topic "characteristics that mark an excellent AHCP." The moderator (WP) used the topic guide to facilitate the discussion and to encourage the participants to contribute equally to the discussion. The other facilitator (IW) was known to most of the participants as a speech therapist, working as a lecturer and researcher in the field of speech therapy. IW, therefore, functioned as a nonparticipating observer, who sat inconspicuously outside the conversation ring. Two observers (speech therapy students of a university) made field notes regarding interactions within the focus group. The first discussion took place at a university campus; the second took place in a regional multidisciplinary center for extramural care; and the third took place in a clinical hospital. Discussions were held in a comfortable room without disturbance. 


\section{Data analysis}

Based on the audio tapes, the observers transcribed the discussion independently under the direct supervision of the facilitator (IW). The observers and the facilitator also carried out data analyses independently. Each examined verbatim text and continually compared text analyses to develop a profile of what constitutes an excellent AHCP, as derived from the perceptions of focus group discussions. These were conducted in a multidisciplinary AHCP setting. The continual cycle of collecting and analyzing data was based on the grounded theory, as described by Hennink et al. ${ }^{20}$ This approach was used, because it provides analytic rigor in interpreting qualitative data and developing empirical theory.

Data analysis procedures began with open coding, which consisted of breaking down data into discrete units of analysis and labeling different units as concepts. Concepts were labeled whenever possible by using the words expressed by participants (ie, in vivo coding). Next, we performed axial coding to reach a higher level of data conceptualization. To achieve this goal, two researchers (WP and IW) independently created items and domains. These domains and items were then compared with each other until a consensus was reached. Analysis of textual data was accomplished by using the qualitative analysis software package ATLAS.ti, version 06 (ATLAS.ti, Scientific Software Development GmbH, Berlin, Germany).

\section{Delphi panel for content validity}

To refine the findings of the focus group sessions and to come to a quantifiable consensus of the characteristics of an excellent AHCP, we developed a survey instrument. The survey was based on the results of the focus group discussions and consisted of domains and items representing an excellent AHCP rated on a three-point scale. We used the Delphi technique according to Lawshe ${ }^{21}$ and invited 35 experts working in some aspect of professional health care to participate in the Delphi survey.

Although the sampling method used was the same as in the focus group design, inclusion criteria were slightly different. To participate in the Delphi survey, respondents did not have to be involved in the actual care of patients in clinical practice. Consequently, we were able to include the following participants in the Delphi panels: senior researchers; publishers in the field of health care; management team members and policy makers; innovators in the field of allied health care; and senior AHCPs specializing in professional talent development. Focus group participants were excluded.
Content-validity ratios were calculated to quantify the degree of consensus in each Delphi panel. Each panelist was asked whether the domains and aspects described in the concept profile, which represented the excellent AHCP, were indeed essential to this profile. The term "domain" refers to a cluster of behaviors, attitudes, and characteristics or the aspects that together form a category.

Domains and aspects in the concept profile were measured, according to the method of Lawshe, ${ }^{21}$ and by using the following scale anchors: "essential;" "important, but not essential;" or "not necessary." The following formula specifies this measurement:

$$
\mathrm{CVR}=\frac{\mathrm{ne}-\mathrm{N} / 2}{\mathrm{~N} / 2}
$$

where CVR is the content-validity ratio, ne is the number of panelists rating a specific item or domain as "essential," and $\mathrm{N}$ is the total number of panelists.

We asked the panelists to express their opinions about the content of the concept profile in two phases. Phase I was based on the focus group results; Phase II was based on modifications derived from the CVR calculation of Phase I. Only items and domains containing positive ratios were considered to be components of the conceptual profile.

We used a similar procedure to determine the placement of the items in the domains. Panelists were asked to assess the correctness of the placement of the items on a four-point Likert scale, where 1 indicates that an item is located correctly and 4 indicates that an item needs to be relocated to another domain. Relocation was carried out, as $\leq 50 \%$ of the panelists assessed an item as located correctly.

The Delphi panel consisted of 29 respondents in Phase I and 27 respondents in Phase II out of the 35 experts that we contacted (response rate, $83 \%$ and $77 \%$, respectively). All respondents met the inclusion criteria in that they were viewed as experts in the field of allied health care, based on the following: an author of publications in the field of policy; or, a researcher in allied health care; and/or, considerable leadership qualities in their specialty. Twelve participants had a bachelor-level education, and 17 had a master's degree. Of the participants, $52 \%$ (15) were female. Their mean (standard deviation) age was 46 (11) years.

\section{Ethical considerations and approval}

In the Netherlands, ethical approval is not required for studies using a focus group design with AHCPs and anonymized 
data analysis. The written information inviting the professionals to participate in the study also included statements describing confidentiality and privacy procedures, the right to refuse participation at any point, and a statement that the sessions would be audiotaped. All participants gave informed oral consent. They were asked to keep any personal information discussed in the focus groups confidential. All data that could have identified participants were removed from the transcripts to guarantee anonymity.

\section{Results}

\section{Results of focus group discussions}

The point of information saturation was identified by using an iterative process, as described by Hennink et al. ${ }^{20}$ The variation in the issues raised after the second focus group session was assessed, and then we continued to collect and assess data to determine whether new information was produced. Data saturation was reached after the assessment of the third focus group session, as no new items were brought up in this session, compared to previous sessions.

The text analysis produced domains describing a theoretical schema based on the experiences, perceptions, and interpretations shared by the participants. Next, we developed a conceptual profile of the "characteristics of an excellent AHCP," using the results from the textual analysis of the focus group discussions, the calculation of both Delphi panel judgment phases (Table 1), and the qualitative interpretation of Delphi panel comments (Figure 1).

The conceptual profile of an excellent AHCP comprises eight attributes or characteristics: cognizance; cooperativity; communicative; initiative; innovative; introspective; broad perspective; and evidence-driven.

\section{Cognizance}

A common issue that surfaced in all three focus group discussions was cognizance, which involves gaining knowledge about a broad multidisciplinary field and then sharing that knowledge, with a focus on delivering quality care and performance. Several participants in focus group one (FG1) and focus group two (FG2) discussed the importance of "knowledge sharing," linking it to attributes, like professional curiosity:

taking initiative; that is an important aspect but also going home with the idea: "I am going to find this out..." [FG2]

Participants also mentioned that taking responsibility for the process, along with reliability and having
Table I Content validity ratios of Delphi panelists judging items of the conceptual framework in the profile of an excellent AHCP

Domains and items in the profile
of an excellent AHCP

Cognizance

Using knowledge in a broad

multidisciplinary field

Sharing knowledge in a

multidisciplinary context

Focused on developing new

knowledge and skills

Focused on quality improvement

in knowledge and skills

Using relevant political or social

developments

Cooperative

Courage to oppose, having the

courage to question others' opinion

in multiprofessional relations

Focused on cooperating with

professionals in various settings

Communicative

Communicating clearly and to the point

Discussing new ideas

Motivating patients/clients

to make choices

Showing the result of one's interactions

Using context-sensible expressions

Showing enthusiasm for one's

profession

Initiative

Acting proactively

Advancing opportunities to change or

to improve based on scientific evidence

Promoting and stressing the distinctive

features of one's profession

Showing vision in entrepreneurship

\section{Innovative}

Making the most of one's abilities

Thinking beyond borders and

"out of the box"

Developing creative alternatives and providing arguments for doing things other than by the protocol

Showing curiosity

\section{Introspective}

Turning personal feedback into

accomplishment

Showing reflectivity and transparency

in one's activities

Keeping within the limits of one's

capabilities

Showing perseverance

Broad perspective

Analyzing complex patient cases

effectively

Acting effectively by integrating

relevant information
Ratio ( $n / N)$ (judged as

“essential" by 27 experts in Delphi round two)

I.00 (27/27)

$0.48(20 / 27)$

$0.78(24 / 27)$

$0.70(23 / 27)$

$0.70(23 / 27)$

$0.19(16 / 27)$

$0.63(22 / 27)$

$0.56(21 / 27)$

$0.93(26 / 27)$

$0.78(24 / 27)$

$0.48(20 / 27)$

$0.26(17 / 27)$

$0.26(17 / 27)$

$0.78(24 / 27)$

$0.48(20 / 27)$

$0.19(16 / 27)$

$0.78(24 / 27)$

$0.70(23 / 27)$

$0.70(23 / 27)$

$0.26(17 / 27)$

$0.56(2 \mathrm{I} / 27)$

$0.63(22 / 27)$

$0.48(20 / 27)$

$0.78(24 / 27)$

$0.78(24 / 27)$

$0.70(23 / 27)$

$0.48(20 / 27)$

$0.93(26 / 27)$

$1.00(27 / 27)$

$0.19(16 / 27)$

$0.19(16 / 27)$

$0.56(2 \mathrm{I} / 27)$

$0.93(26 / 27)$

$0.78(24 / 27)$
(Continued) 
Table I (Continued)

\begin{tabular}{ll}
\hline $\begin{array}{l}\text { Domains and items in the profile } \\
\text { of an excellent AHCP }\end{array}$ & $\begin{array}{l}\text { Ratio (n/N) (judged as } \\
\text { “essential” by 27 experts } \\
\text { in Delphi round two) }\end{array}$ \\
\hline $\begin{array}{l}\text { Acting effectively in complex situations } \\
\text { Able to effectively distinguish main }\end{array}$ & $0.70(23 / 27)$ \\
$\begin{array}{l}\text { issues from side issues in complex } \\
\text { situations }\end{array}$ & $0.93(26 / 27)$ \\
$\begin{array}{l}\text { Evidence-driven } \\
\text { Applying principles of evidence-based } \\
\text { practice }\end{array}$ & $\mathbf{0 . 7 8 ( 2 4 / 2 7 )}$ \\
$\begin{array}{l}\text { Justifying one's professional } \\
\text { interferences }\end{array}$ & $0.93(26 / 27)$ \\
Seeking and finding scientific knowledge & $0.78(24 / 27)$ \\
\hline
\end{tabular}

Abbreviation: AHCP, allied health care professional.

a broad foundation of knowledge, is associated with being an excellent professional. One of the participants mentioned:

[...] always looking, searching for new knowledge, new sources. [FG1]

An excellent professional is a "knowledge searcher." [FG3]

\section{Cooperativity}

An essential attribute of an excellent AHCP is being cooperative: the ability to effectively work with others in multidisciplinary, complex clinical situations. This included having the courage to oppose and to question someone else's opinion and persuading others to make difficult choices. This notion of being willing to cooperate with others without compromising the quality of care was mentioned in all three focus group sessions:

Find connections within your own profession and beyond.

[FG3]

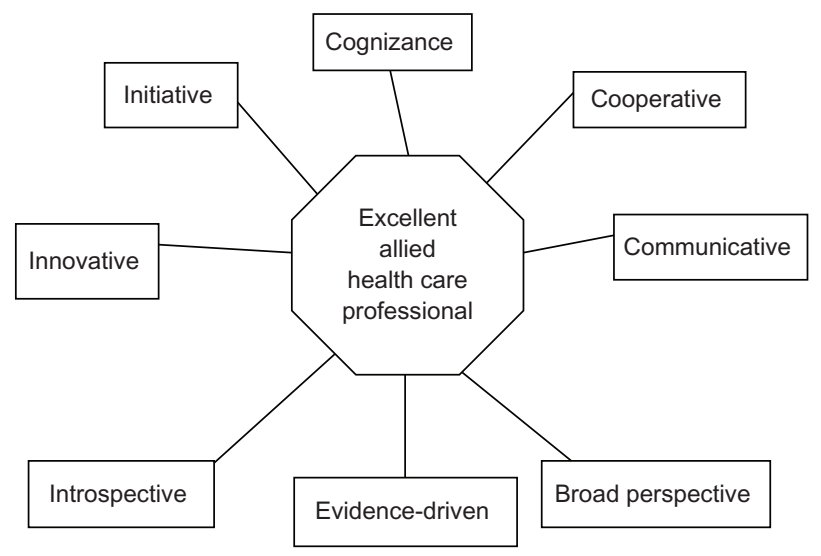

Figure I Characteristics of an excellent health care professional: a conceptual profile.
People who keep asking colleagues questions, and constantly wanting to know "why?" [FG1]

[...] considering the best way to work together. [FG2]

Cooperating is essential for excellent care. [FG2]

\section{Communicative}

Excellent AHCPs need to be able to communicate on different levels and in complex situations. All three focus groups agreed that an excellent AHCP is always a proficient communicator, one who is able to "summarize patients' needs" (FG1, FG3) and to assist them in making choices (FG1):

He is a capable listener. [He] paraphrases and asks questions to come to the core of the message in multidisciplinary discussions. [FG1, FG2]

Modulating to the level of understanding of patients. [FG1]

[And] showing respect and empathy while diagnosing or intervening in complex situations was brought up as well. [FG2]

\section{Initiative}

Another quality of an excellent AHCP is the ability to propose and promote new ideas, act proactively, and follow them through. Proactive behavior was seen as "acting in advance of a future situation, rather than just reacting" (FG2). An excellent professional initiates processes of change and is an advocator of his or her profession within and outside his own professional field or organization. One participant noted the following:

[An excellent AHCP] is [capable of] influencing the organization remarkably [cross talk], bringing in new thoughts and things [cross talk]. [FG3]

Starting up new ideas in practice. [FG1]

\section{Innovative}

An excellent AHCP is able to devise new ideas and implement alternatives beyond current practices. All three groups viewed the ability to innovate as an important domain for the excellent professional. An excellent AHCP's innovativeness is related to continuously seeking to realize quality of care improvements. It is essential not only to go beyond the usual codes of one's profession, but also "to have an eye for unbeaten paths" (FG3). "Supporting innovations, implementing ongoing creative alternatives," and "[...] being open to renewal" (FG2) are elements of this domain. 


\section{Introspective}

Another characteristic of an excellent AHCP is the ability to reflect, being able to examine one's self contemplatively. Participants considered introspection, reflection, and contemplation to be related to self-examination of one's conscious thoughts and the rational self-assessment of one's capabilities and limits. These traits are important determinants of excellent professionals (FG2, FG3). "Introspection" was not referenced in a spiritual context or explained as a philosophical concept, but focus group participants considered it to be essential if one is to provide high-quality care. This notion was emphasized by one participant:

[An excellent AHCP] is constantly asking, evaluating, "am I on the right track?" [They keep] searching reflectively for a solution. [FG1]

\section{Broad perspective}

An excellent AHCP can obtain an overall perspective of complex situations (FG1, FG2, and FG3). He or she is able to see the big picture and operational implications. "Having a helicopter view [or bird's eye view]" was mentioned several times (FG2 and FG3). "Excellent professionals are able to supervise activities" (FG2) to direct or manage complex processes and "to take the lead in multidisciplinary matters" (FG3). Being able to provide an overview of new complex (clinical) situations and to put this impression in broad perspective refers to the capacity of excellent professionals to tell the difference between major and minor issues (FG1, FG2, and FG3). The concept of having a broad perspective was sometimes associated with the term "effectiveness," as this reflects the need to integrate new relevant information and to act efficiently in complex situations:

[...] it has to do with the helicopter view, and analysis, and different perspectives you offer. [FG2]

[...] to keep an overview, to continue to see the broad perspective. [FG1]

\section{Evidence-driven}

An excellent AHCP is able to underpin his or her decisions with scientific evidence. This involves the ability to find appropriate evidence and to use that evidence to guide professional interventions (FG1, FG2, and FG3). This is exemplified in the comments of several focus group participants:

[It's the ability] to justify one's intervention. [FG3]

Excellent AHCPs do not have to be researchers or active as master's in science. [FG1]
But they collect and disseminate available scientific evidence in the health care domain for the reason that they are willing to provide the best care available in a specific health care situation. [FG2]

[The AHCP] is interested in applying research outcomes to clinical practice. [FG3]

\section{General remarks}

Several focus group participants mentioned that it was difficult to satisfactorily describe their perceptions of an excellent AHCP, especially in choosing words that would clearly describe characteristics as knowledge, attitude, disposition, performance, and interference. This was exemplified by one participant: "I think excellent professionals are motivated $[\ldots]$. They can surpass themselves [...]. But yeah, how do you say this less indistinctly ...?" (FG2).

"What is your opinion regarding the difference between an expert AHCP and an excellent AHCP?" The answers to the question provided additional information regarding the concept of "excellent professional." Participants stated that there is a noteworthy difference between the two in that an expert is someone who knows a lot about a particular issue or about a single specialty and that an excellent professional is someone who possesses a set of supervised, interrelated competencies in a large area. As one participant declared:

One can be an expert and not be an excellent [professional].

He or she "just" knows a remarkable amount about a topic of interest [...]. [FG1]

Other participants mentioned that an excellent professional can be an expert as well, but she or he does not have to be. However, an excellent professional undeniably is always a competent communicator, where an expert does not always have to be. All participants agreed on this distinction, as was proposed by the moderator.

\section{Results of the Delphi panels}

There were only a few differences between the opinions of those participating in the focus groups and experts participating in the Delphi panels. A minority ( $\leq 50 \%$ ) of the panelists regarded "showing empathy in complex situations" (ratio $[\mathrm{r}]=-0.03$ ), "showing leadership by inspiring and stimulating new ideas in others" ( $\mathrm{r}=-0.17)$, "daring to take risks" $(\mathrm{r}=-0.38)$, and "defending team members/colleagues" $(r=-0.45)$ as essential components for the profile of an excellent AHCP. Therefore, as the panelists did not unanimously support these items and for validity reasons, we concluded that these items should not be included in the profile. On the basis of qualitative analysis 
of the Delphi panelists' comments, we reworded several items in a clearer and more active way. Also, after re-reviewing the transcripts and the Delphi panelists' comments, we included the domain "cooperative" $(r=0.63)$ in the profile (Table 1).

After the second Delphi phase, all items were localized to the correct domain, as more than $50 \%$ of the panelists assessed the location of the items in the domains as correct (Figure 1).

\section{Discussion}

We identified 32 items in eight domains that describe an excellent AHCP. From these domains, we developed a conceptual profile - "characteristics of an excellent health care professional" (Figure 1). The results of our study generally agree with those of Benner, ${ }^{10}$ Alsop, ${ }^{6}$ Mieg, ${ }^{7}$ and Courtney. ${ }^{5}$ However, our descriptions of what constitutes an excellent AHCP are more detailed and specific.

An excellent AHCP acts and responds appropriately in different situations (eg, complex or new situations) by using a set of particular competencies. Comparing our results to Lovecky's ${ }^{13}$ theory of "gifted adults," we find both similarities and differences. Lovecky uses the term "excitability" to describe the work ethic of gifted adults; that is, they work "tirelessly" when they encounter an intellectual challenge. ${ }^{13}$ She uses the term "entelechy" to denote their powerful drive to achieve self-actualization, to "be cognizant in a broad multidisciplinary field." 13 These findings are in general agreement with ours. We used the term "introspective" to describe how an excellent AHCP is able to assess himself and his motivations and abilities. "Cognizance" was used to describe his capacity for gaining broad knowledge about a multidisciplinary field and then sharing it with others.

The participants in our focus groups did not discuss whether the features that characterize an excellent AHCP could also contribute to conflicts in their lives. They might have viewed "gifted" or "outstanding medical learners" - that is, those who score in the top percentiles on standardized intelligence quotient (IQ) tests - and excellent professionals to be very different. Although an excellent professional does not need to have a superior IQ, they are capable of interacting practically, creatively, and proactively in complex situations. This is in line with the opinion of Sternberg: ${ }^{11}$ that both cognitive expertise and social expertise are needed when it comes to job performance. This opinion can be seen as relevant for professionals as well as for students.

The results of our study may be important for understanding how to deliver better quality care and how to improve patient safety. There seems to be an association between having a broad foundation of knowledge at one's disposal and the ability to use one's competencies reasonably in complex clinical situations, thereby preventing adverse events in hospitalized patients. ${ }^{22-24}$ Therefore, we hypothesize that excellent AHCPs can have a positive influence on patient safety as well. This idea, however, needs to be studied further.

The participants in our study occasionally expressed their ideas about what characterizes an excellent professional in negative terms: what is not excellent. For example, "I think an excellent professional does not take protocols for granted" (FG1). The moderator then asked the participants to rephrase their opinions, asking them to simply list the characteristics instead of stating what an excellent AHCP is not. The participants responded accordingly by stating, for instance, "I mean, they want to summarize patients' needs ... . They make sure of themselves by seeking evidence" (FG1).

We asked participants to join focus groups in a multiprofessional health care setting. Therefore, at the end of the discussions, they were asked whether this multiprofessional approach might have hampered the discussion, since some determinants of an excellent professional may uniquely fit one profession but not others. In three of the focus groups, participants unanimously agreed that this approach did not inhibit the discussion. Indeed, they believed that conducting the discussion in a multidisciplinary setting was richer and more inspiring, and that irrelevant issues relating to other health care professions did not come up.

As we were analyzing the various domains and items, we separated the domain "initiative/innovative" as two different domains - "initiative" and "innovative" - because it was previously viewed as one domain. The Delphi panel results supported this distinction. In the context of an excellent AHCP, initiative relates to one's ability to advance new ideas. On the other hand, innovative relates to the whole process of implementing new and meaningful ideas and procedures. A similar discussion occurred for the domains "cognizance" and "evidence-driven." Several focus group members clarified and distinguished these two concepts, with cognizance referring to the gaining and sharing of knowledge, and "evidence-driven," referring to finding and using scientific evidence to guide one's decisions.

\section{Limitations}

It may be suggested that three focus group sessions is limited. As this study was situated in a larger study toward excellence in five other professions as well - we carried out 15 focus groups in total - we were able to estimate that, in the third focus group, data saturation was reached. This study was 
limited by employing a convenience (snowball) sample and its focus on only five health care professions. However, it is reassuring that most of the words, domains, and issues discussed within the Delphi phases reflect the core importance of the domains/words as mentioned by the focus groups. We did not use member check or participant feedback to see whether the participants recognized the results. We concluded that this was not required because most of the results were homogeneous, and external validation was performed by using a Delphi method in which consensus was reached.

\section{Conclusion}

Using a focus group design in this study, augmented by a Delphi panel method, we were able to produce a conceptual profile of what constitutes an excellent AHCP. This was done with acceptable content validity ratios. The profile can be used as a reference for personal improvement for supervisors and professionals in clinical practice and for educational purposes. This profile may serve as a guide against which talented students can evaluate themselves. Such guided reflection may inspire students to improve their attitudes and competencies, with the goal of becoming an excellent professional in health care. Thereby, it can be important to be attentive to what constitutes an excellent health care professional in staffing decisions about improving excellence in a multidisciplinary team setting with regard to care quality and patient safety. Future research is needed to determine how this profile of an excellent AHCP can be put to practical use; for instance, as a reflective model for students and novice professionals, and on behalf of curriculum developers in higher education. Moreover, further research is needed in what circumstances the profile can be implemented.

\section{Acknowledgments}

The authors are grateful to all participants involved in the focus groups as well as those involved in the expert panels. The authors thank the Dutch Sirius organization for additional funding of the research project.

\section{Disclosure}

The authors declare that ethical approval by an ethical committee was not required for this study. The authors also declare no conflicts of interest.

\section{References}

1. paramedisch.org [homepage on the Internet]. Nederlands Paramedisch Instituut (NPI); 2012 [updated May 1, 2012; cited June 17, 2012]. Available from: http://www.paramedisch.org/onderzoek-en-ontwikkeling/ verslaglegging.html. Accessed June 7, 2012. Dutch.
2. rvz.net [homepage on the Internet]. Raad voor de Volksgezondheid. Ministry of Health; 2011 [updated July 27, 2011; cited June 17, 2012]. Available from: http://rvz.net/publicaties/bekijk/bekwaam-is-bevoegd. Accessed June 7, 2012.

3. Raad voor de Volksgezondheid. Perspectief op gezondheid 20/20 [Perspective on health 20/20]. The Hague: Ministry of Health; 2010. Available from: http://rvz.net/uploads/docs/Advies_-_Perspectief_op_ gezondheid.pdf. Accessed June 7, 2012. Dutch.

4. Jost SG, Bonnell M, Chacko SJ, Parkinson DL. Integrated primary nursing: a care delivery model for the 21 st-century knowledge worker. Nurs Adm Q. 2010;34(3):208-216.

5. Courtney M. The meaning of professional excellence for private practitioners in occupational therapy. Aust Occup Ther J. 2005;52(3):211-217.

6. Alsop A. The leading edge of competence: developing your potential for advanced practice. In: Brown G, Esdaile SA, Ryan E, editors. Becoming an Advanced Healthcare Practitioner. London, UK: ButterworthHeinemann; 2003:260-281.

7. Mieg HA. Two factors of expertise? Excellence and professionalism of environmental experts. High Ability Studies. 2009;20(1):91-115.

8. Feltovich PJ, Prietula MJ, Ericsson KA. Studies of expertise from psychological perspectives. In: Ericsson KA, Charness N, Hoffman RR, Feltovich PJ, editors. The Cambridge Handbook of Expertise and Expert Performance. Cambridge, UK: Cambridge University Press; 2006:41-68.

9. Ericsson KA, editor. The Road to Excellence: The Acquisition of Expert Performance in Arts and Sciences, Sports and Games. Hillsdale, NJ: Lawrence Erlbaum Associates; 1996.

10. Benner P. From Novice to Expert: Excellence and Power in Clinical Nursing Practice. Menlo Park, CA: Addison Wesley Company; 2001.

11. Sternberg RJ. Giftedness as developing expertise: a theory of the interface between high abilities and achieved excellence. High Ability Studies. 2001;12(2):159-179.

12. Dweck CS. Self-Theories: Their Role in Personality, Motivation, and Development. (Essays in Social Psychology). Philadelphia, PA, Psychology Press. 1999:115-135.

13. Lovecky DV. Can you hear the flowers sing? Issues for gifted adults. Journal of Counseling and Development. 1986;64(9):572-575.

14. Wilhelmsson M, Pelling S, Uhlin L, Owe Dahlgren L, Faresjö T, Forslund K. How to think about interprofessional competence: a metacognitive model. J Interprof Care. 2012;26(2):85-91.

15. Courtney M, Farnworth L. Professional competence for private practitioners in occupational therapy. Aust Occup Ther J. 2003;50(4): 234-243.

16. Brown G, Esdaile SA, Ryan SE. Becoming an Advanced Healthcare Practitioner. London: Butterworth-Heinemann; 2003.

17. Hartshorn JC, Berbiglia VA, Heye M. An honors program: directing our future leaders. J Nurs Educ. 1997;36(4):187-189.

18. American Association of Critical-Care Nurses. AACN standards for establishing and sustaining healthy work environments: a journey to excellence. Am J Crit Care. 2005;14(3):187-197.

19. Liamputtong P, Ezzy D. Qualitative Research Methods. 2nd ed. NY, NY: Oxford University Press; 2006.

20. Hennink M, Hutter I, Bailey A. Qualitative Research Methods. Los Angeles, CA: SAGE Publishers Ltd; 2011.

21. Lawshe $\mathrm{CH}$. A quantitative approach to content validity. Personnel Psychology. 1975;28(4):563-575.

22. Zeegers HWM. Adverse Events Among Hospitalized Patients. Results and Methodological Aspects of a Record Review Study [doctoral thesis]. Vrije Universiteit, Amsterdam; 2009.

23. Paans W. Accuracy of Nursing Diagnoses: Knowledge, Knowledge Sources and Reasoning Skills [doctoral thesis]. G Van Ark, Haren, the Netherlands: Catholic University Leuven; 2011.

24. Paans W, Sermeus W, Nieweg RM, Krijnen WP, van der Schans CP. Do knowledge, knowledge sources and reasoning skills affect the accuracy of nursing diagnoses? A randomized study. BMC Nurs. 2012;11:11. 


\section{Publish your work in this journal}

The Journal of Multidisciplinary Healthcare is an international, peerreviewed open-access journal that aims to represent and publish research in healthcare areas delivered by practitioners of different disciplines. This includes studies and reviews conducted by multidisciplinary teams as well as research which evaluates the results or conduct of such teams or health-

care processes in general. The journal covers a wide range of areas and welcomes submission from practitioners at all levels, from all over the world. The manuscript management system is completely online and includes a very quick and fair peer-review system. Visit http://www.dovepress. com/testimonials.php to read real quotes from published authors.

Submit your manuscript here: http://www.dovepress.com/journal-of-multidisciplinary-healthcare-journal 